\title{
EFFECT OF ACID EVAPORATION IN CHEMICALLY AMPLIFIED RESISTS ON INSOLUBLE LAYER FORMATION
}

\author{
NAOKO KIHARA, SATOSHI SAITO, TOHRU USHIROGOUCHI, and MAKOTO NAKASE \\ Research and Development Center, Toshiba Corporation, \\ 1, Komukai Toshiba-cho, Saiwai-ku, Kawasaki 210, Japan
}

This paper concerns the acid evaporation caused by the baking treatment of chemically amplified resists. The evaporation of photogenerated acid during the post-exposure-baking (PEB) process was measured as a spectral change of indicator film that consisted of polyvinyl alcohol (PVA) and tetrabromophenol blue sodium salt (TBPB). Using this method, it was observed that the amount of evaporated acid depended on the pre-baking and PEB conditions. A high temperature pre-baking before exposure reduced the amount of evaporated acid. By contrast, a high temperature PEB accelerated the acid evaporation, and the thickness of the insoluble layer increases with increasing PEB temperature. These results suggest that acid evaporation is concerned with the formation of the insoluble layer.

\section{Introduction}

Chemically amplified resists are the most promising materials for the fabrication of nextgeneration LSIs. However, the main impediment to putting a chemically amplified positive-tone resist into practical use is its susceptibility to process conditions and environments. The performance of a chemically amplified resist is influenced by a host of factors and the acidcatalyzed thermal reaction induced by heat treatment is affected by the internal and external conditions of the resist film. The main external factor is deactivation of the generated acid by airborn contamination, ${ }^{1,2}$ and the internal factors are, for example, inhomogeneous dispersion of resist components and evaporation of volatile substances from the resist surface during thermal treatment. $^{3}$

Few reports have mentioned the effect of acid evaporation from the resist film on resist performance. ${ }^{4.5}$ Röshert $e t$ al. reported the loss of acid from a resist surface during PEB using the Sandwich "Blue" Test method." The resist film was, however, in contact with the indicator film. 
To avoid the influence of the acid migration between the solid matrixes during measurement of the vaporized acid from the resist surface, the present authors here employed a method that provides a space between the indicator film and the resist film. ${ }^{6}$ For this purpose, a very thin indicator film, sufficiently sensitive for the detection of acid vaporized from the resist, was prepared in this work.

Thermal treatment during the resist process is expected to have the effect not only of accelerating the acid-catalyzed reactions but also of changing the concentration of volatile substances. A general chemically amplified resist process from coating to development contains at least two baking treatments. The first is a pre-baking to eliminate the solvent from a film coated onto a substrate, and the second is a post-exposure-bake (PEB) to accelerate acid-catalyzed thermal reactions. The evaporation of photo-generated acid occurs during PEB, but it is thought that both baking processes may influence the evaporation. With this in mind, the authors investigated the effect of baking conditions on acid evaporation.

In this paper, the authors report the method of detecting the evaporated acid in chemically amplified positive-tone resist containing triphenylsulfonium triflate (TPS-OTf) as a photo-acid generator. Using this method, the relation between the thermal treatment of the resist film and the mode of the acid evaporation during the PEB process was investigated. The effect of the acid evaporation on insoluble layer formation is also discussed.

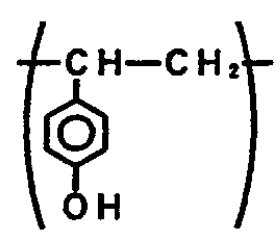

PHS

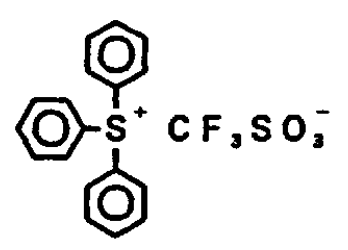

TPS-OT f

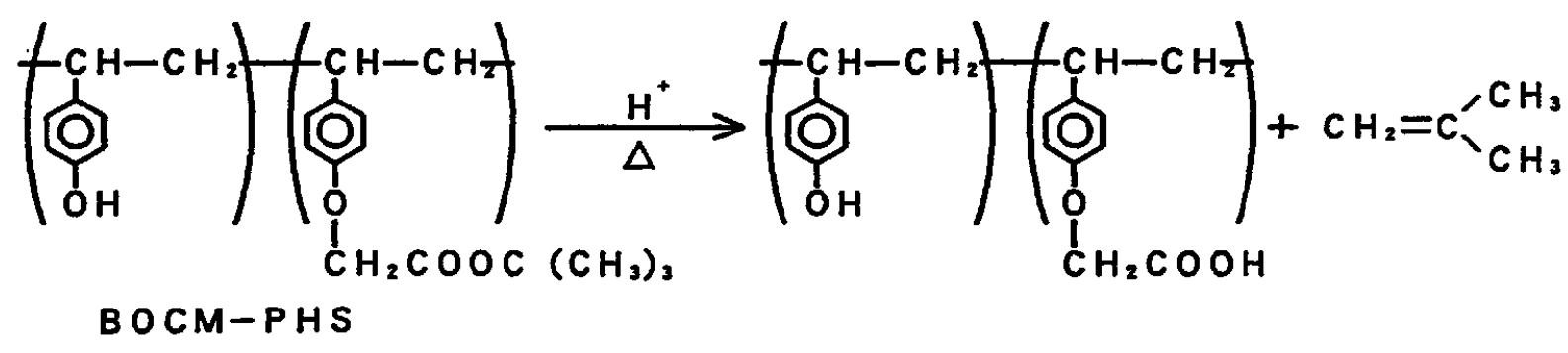

Scheme 1 Structure of resist components 


\section{Experimental}

\subsection{Materials and processing}

The poly(4-hydroxystyrene) (PHS) and acid generator (TPS-OTf), utilized in this work were purchased from commercial sources. The random copolymer, poly(p-t-butoxycarbonylmethoxystyrene)-co-poly(4-hydroxystyrene) (BOCM-PHS) utilized in this study was synthesized according to the literature. ${ }^{7}$ The structures of the resist components are shown in Scheme 1.

The PHS, BOCM-PHS and acid generator described above were dissolved in 1-acetoxy-2ethoxyethane (ECA). After filtration, the resist solution was spin-coated onto silicon wafers and was baked on a hot plate.

Three resist samples PV-5, IH-5, and IH-1 were prepared and their compositions are listed in Table 1.

The acid indicator film was prepared as follows: an aqueous solution of $1.25 \mathrm{wt} \%$ of PVA and 1.25 wt\% of TBPB was filtered and then spin-coated onto a quartz wafer and baked on a hot plate at $100{ }^{\circ} \mathrm{C}$ for 2 min. The structures of the materials utilized for preparing the indicator film are shown in<smiles>CC(C)C(C)C(C)C</smiles>

PVA

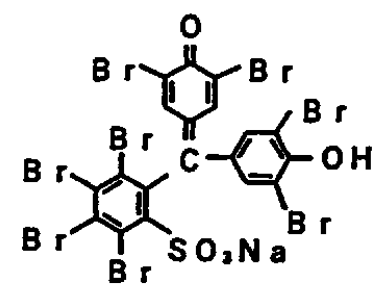

T B P B

Scheme 2 Structure of indicator film components

\subsection{Measurement method of evaporated acid}

UV exposure was carried out using a high pressure mercury lamp equipped with a $251 \mathrm{~nm}$ filter (Toshiba Glass Co., Ltd.). During PEB, the indicator film coated on the quartz wafer was set opposite to the exposed resist film. The gap between the indicator film and the exposed resist film was set by a spacer of $50 \mu \mathrm{m}$-thick teflon
Table 1 Composition of prepared resist

\begin{tabular}{|c|c|c|}
\hline Name & Polymer & $\begin{array}{c}\text { Content of } \\
\text { TPS-OTf } \\
\text { (wt\%) }\end{array}$ \\
\hline PV-5 & PHS & 5.0 \\
\hline IH-5 & BOCM-PHS & 5.0 \\
\hline IH-1 & BOCM-PHS & 1.0 \\
\hline
\end{tabular}


film. UV-visible absorption spectra were measured on a UV-3101PC spectrometer (Shimadzu Corp.).

The dissolution rate of the resist films into an alkaline developer was measured using a 5900 Development Rate Monitor (Perkin-Elmer Co., Ltd.). $1.67 \%$ tetramethyl ammonium hydroxide aqueous solution was used as a developer.

\section{Results and discussion}

3.1 Evaporated acid detection by acid indicator film

A thin film which consisted of PVA and TBPB was employed as an acid vapor detector. The visible-absorption of TBPB in PVA film exhibits an absorption maximum at $629 \mathrm{~nm}$.

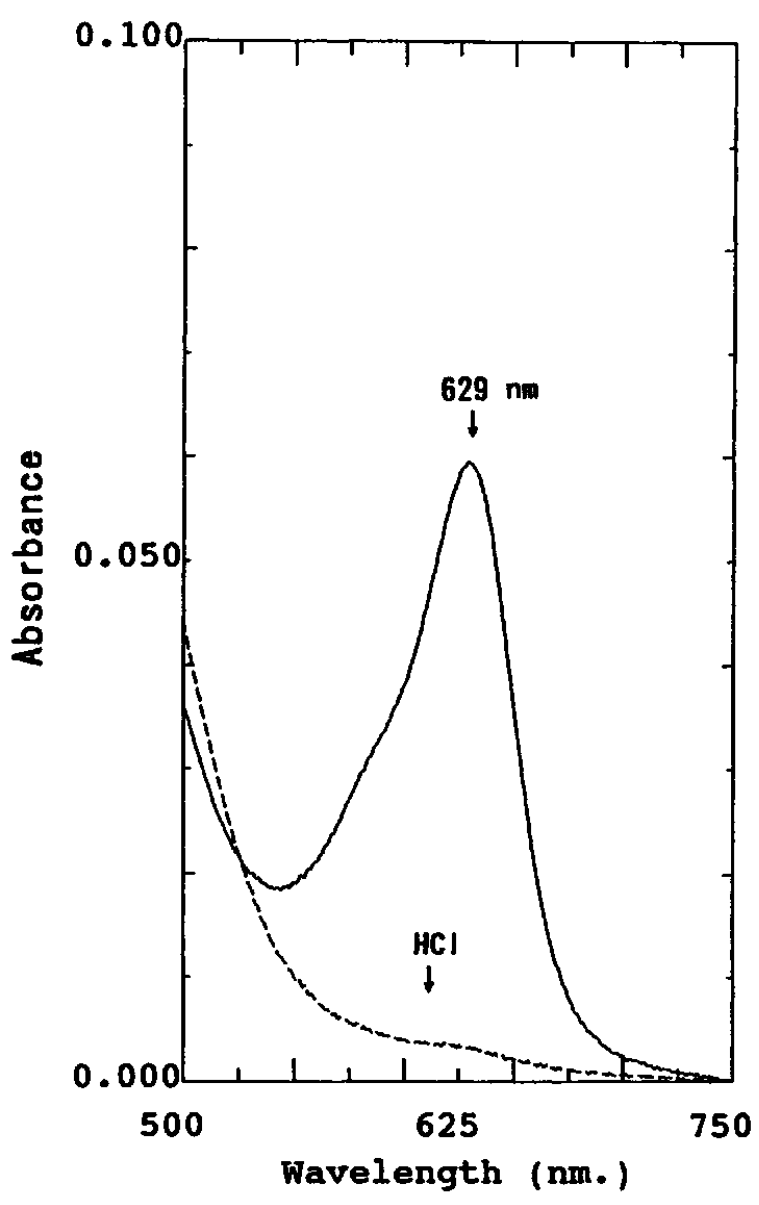

Fig. 1 Spectral change of indicator film

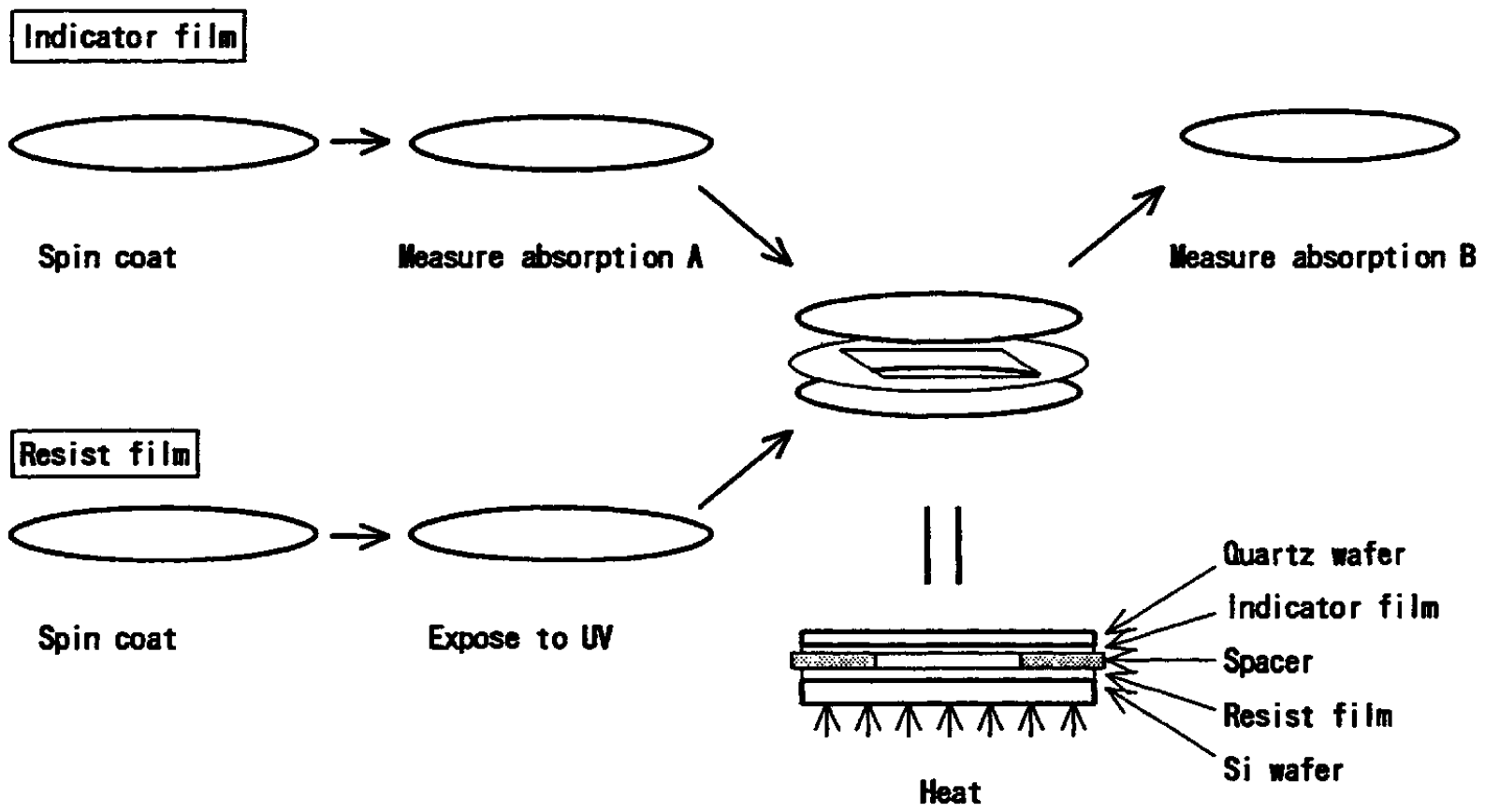

Fig. 2 Process for measurement of acid evaporation 
To confirm the behavior of this film under acidic vapor, the film was exposed to hydrogen chloride which was produced by sulfuric acid and hydrochloric acid.

As shown in Fig. 1, the absorption band at $629 \mathrm{~nm}$ of the film is bleached on exposure to hydrogen chloride. From this result, it has been confirmed that the film is suitable as a detector for acidic vapor. Figure 2 shows the process sequence of the measurement of the acid evaporation. Indexed against the amount of evaporated acid, the bleaching ratio obtained from absorption $\mathrm{A}$ and absorption B was used.

The bleaching ratio change was investigated when the exposure dose was varied between 0 and $150 \mathrm{~mJ} / \mathrm{cm}^{2}$. Figure 3 shows the spectral change of the indicator films, where the exposure dose was a parameter. As shown in Fig. 4, the bleaching ratio that was calculated from Fig.3 increased with increasing exposure dose and steadied at dose of more than $50 \mathrm{~mJ} / \mathrm{cm}^{2}$. This fact shows that the bleaching of the indicator film was caused by the vaporized acid which was generated by UV irradiation.

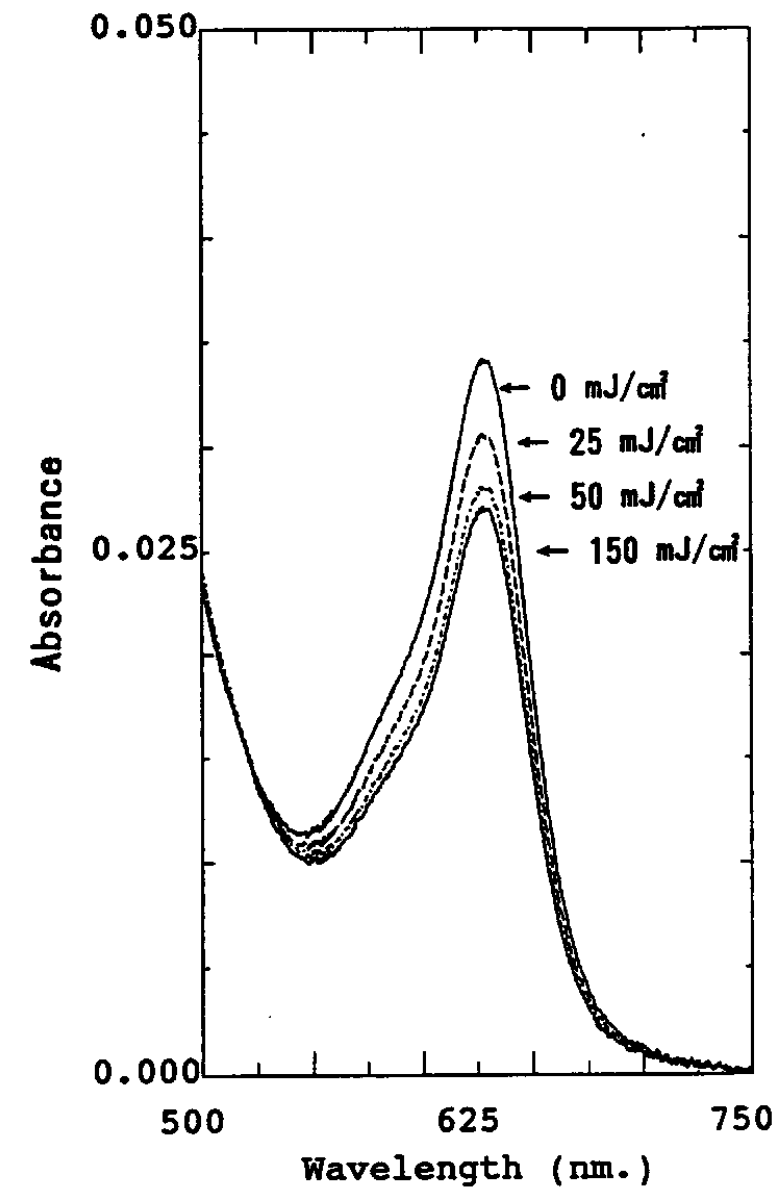

Fig. 3 Spectral change of indicator film
To obtain clearer spectral change of indicator film, the resist film was exposed at a dose of $100 \mathrm{~mJ} / \mathrm{cm}^{2}$ in the following experiments.

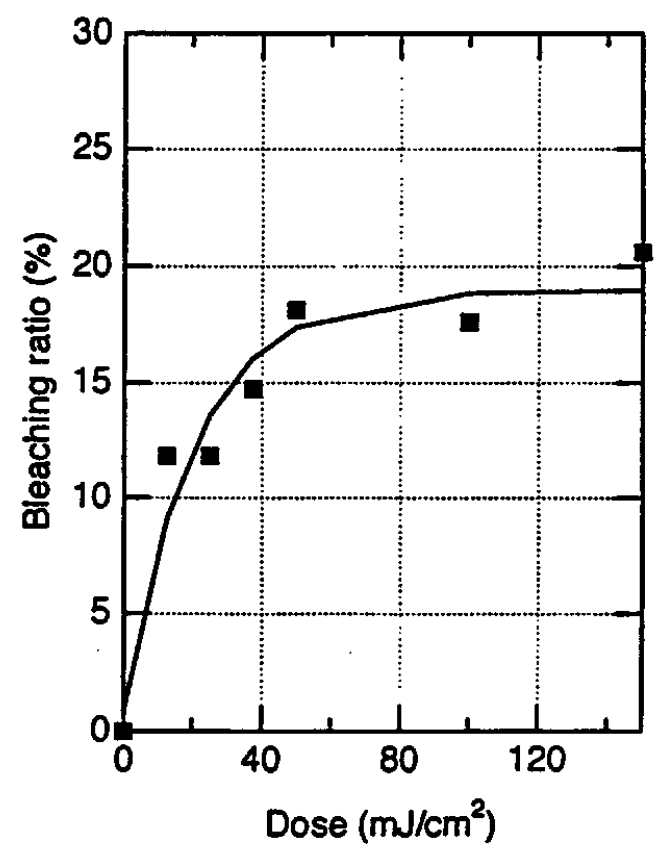

Fig. 4 Relation between exposure dose and bleaching ratio of indicator film : pre-bake $120^{\circ} \mathrm{C}$ for $4 \mathrm{~min}$. PEB at $90^{\circ} \mathrm{C}$ for $5 \mathrm{~min}$. 
3.2 Effect of pre-baking conditions

To observe the effect of pre-baking condition, it is necessary to eliminate the other acceleration factors. For this reason, PV-5 which did not contain an acid-labile group was utilized as a resist to investigate the pre-baking effect.

The relationship between the bleaching ratio and the pre-baking temperature is shown in Fig. 5. The pre-baking temperature was varied from 80 to $130^{\circ} \mathrm{C}$. Then the resist film was exposed to deep-UV at a dose of $100 \mathrm{~mJ} / \mathrm{cm}^{2}$. After exposure, the resist film was baked on a hot plate by using the process explained in Fig.

2. It has been found that the bleaching ratio was reduced by increase of the pre-baking temperature and steadied at around $110^{\circ} \mathrm{C}$. This

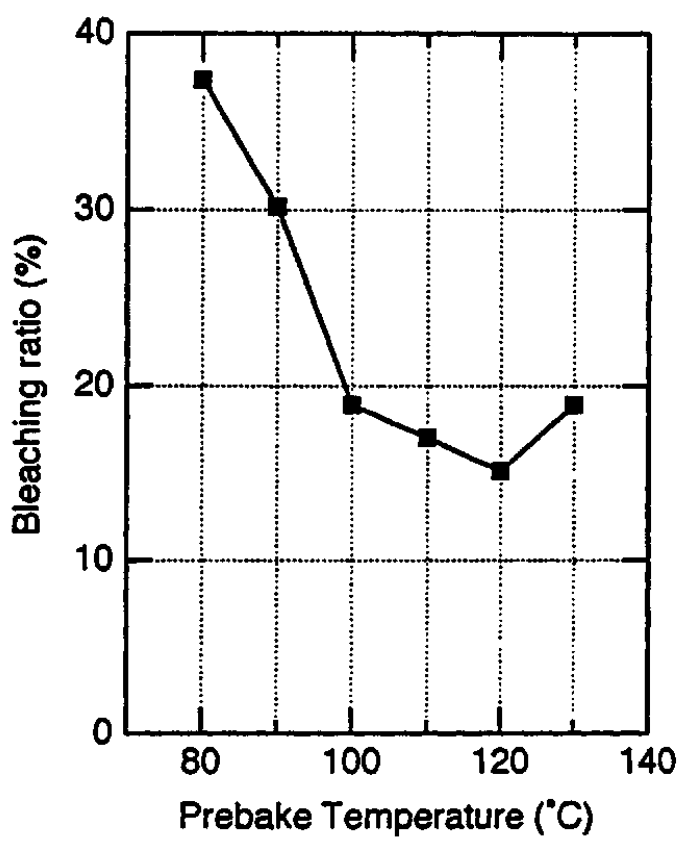

Fig. 5 Relationship between bleaching ratio and pre-baking temperature : PEB at $80^{\circ} \mathrm{C}$ for 5 min. result indicates that the pre-baking conditions affect acid evaporation.

One of the volatile compounds in the exposed resist film beside the photolysis products is residual solvent. The effect of remaining solvent in chemically amplified resist films for thermal reaction was investigated by Asakawa, et al. ${ }^{8}$ They reported that the amount of remaining ECA in resist film decreases with increasing pre-bake temperature, and steadies when the film is prebaked at temperatures higher than around $110^{\circ} \mathrm{C}$. This tendency is similar to that of the acid evaporation case shown in Fig. 5. From this fact, it is expected that the remaining solvent would provide the pathway for vaporizing acid, or in some cases make an azeotropic mixture.

\subsection{Effect of PEB temperature on acid evaporation}

The relationship between the PEB temperature and the acid evaporation was investigated. In this experiment, to obtain the tendency of the acid evaporation in conformity with the practical application, IH-5 containing the BOCM-PHS was utilized as a resist. To avoid the affect of residual solvent, pre-baking was carried out at $120^{\circ} \mathrm{C}$ for $4 \mathrm{~min}$. 


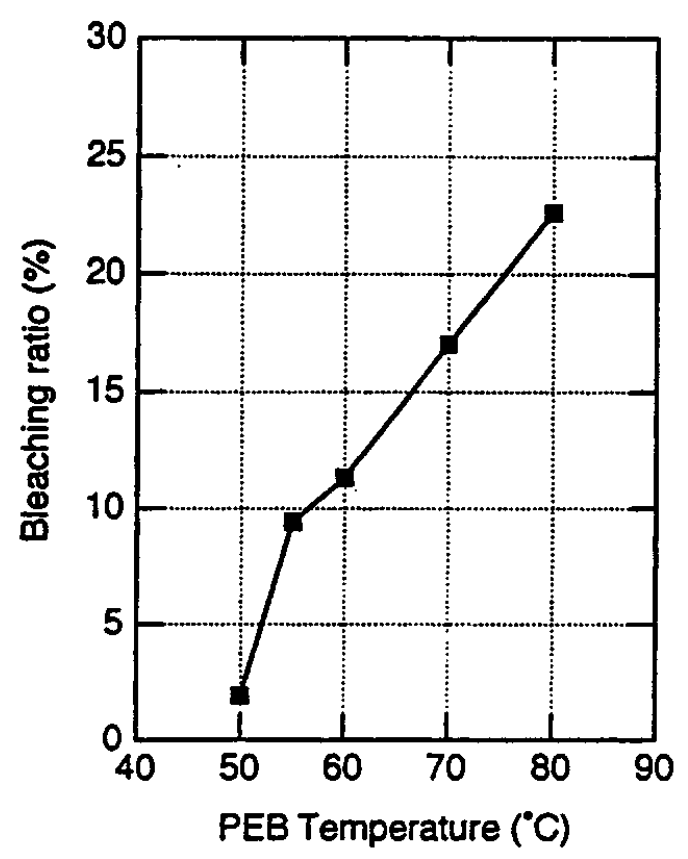

Fig. 6 Relationship between PEB temperature and bleaching ratio

Figure 6 shows the relationship between the PEB temperature and the amount of the evaporated acid. The bleaching ratio of the indicator film increases when the PEB temperature becomes higher.

These results suggest that PEB treatment at low temperature is effective to suppress the acid evaporation from resist surface.

\subsection{Relationship between acid evaporation and insoluble layer formation}

To study the efficiency of the acid evaporation on the insoluble layer formation, the dissolution properties of the resist films were individually measured at PEB temperatures of 50, 60 and $70^{\circ} \mathrm{C}$ where $\mathrm{IH}-1$ containing 1 wt\% of TPS-OTf was used to obtain a dissolution rate appropriate to the alkaline developer. The PEB temperature dependence of dissolution characteristics are shown in Fig. 7, from which it may be seen that the thickness of the low dissolution rate layer, $T_{i}$, was observed to increase with increasing PEB temperature. 
Figure 8 shows the relationship between the bleaching ratio and the insoluble layer thickness, where the PEB temperature is as a parameter.

The value of the bleaching ratio and $T_{i}$ were obtained from Fig.s 6 and 7, respectively. The insoluble layer thickness increases with increasing the bleaching ratio. Based on this result, it is expected that the evaporation of acid would alter the thermal decomposition ratio of the dissolution inhibitor in resist film surface.

\section{Conclusion}

Acid evaporation from the resist film during

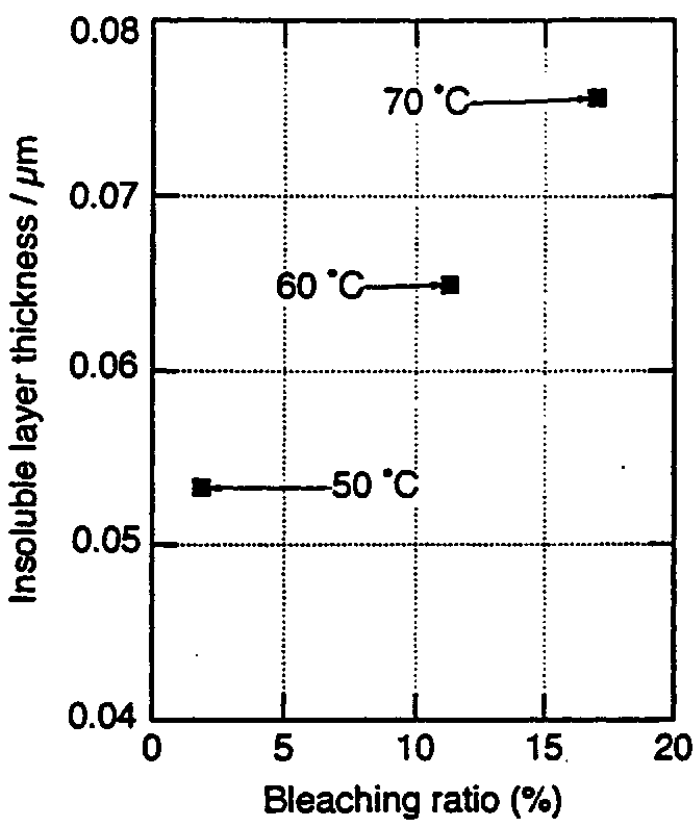

Fig. 8 Relation between bleaching ratio and insoluble layer thickness the PEB has been observed by spectral change of indicator film set on the resist film. It is apparent that the photo-generated acid vaporizes during the PEB process.

Acid evaporation was stimulated by the volatile compositions in the resist film such as products formed by photo-induced reactions or residual solvents.

When the pre-baking was carried out at temperatures higher than $110^{\circ} \mathrm{C}$ to reduce the residual solvent, the amount of the evaporated acid remained at the depressed level. It was also found that the insoluble layer thickness of the resist film increased with increasing PEB temperature. The results show that high temperature pre-baking and low temperature PEB can suppress the acid evaporation that enhances the insoluble layer formation.

\section{References}

1. S. A. MacDonald, N. J. Clecak, H. R. Wendt, C. G. Willson, C. D. Snyder, C. J. Knors, N. B. Deyoe, J. G. Maltabes, J. R. Morrow, A. E. McGuire, S. J. Holmes, Proc. of SPIE, 1466, 2 (1991). 2. W. D. Hinsberg, S. A. MacDonald, N. J. Clecak, C. D. Snyder, Proc. of SPIE, 1672, 24 (1992). 3. N. Oyasato, H. Niki, R. Hayase, Y. Onishi, M. Nakase, The 53rd Autumn Meeting of JSAP (1992) $17 \mathrm{p}-\mathrm{ZM}-4$.

4. J. W. Thackeray, T. H. Fedynyshyn, A. A. Lamola, R. D. Small, J. Photopolym. Sci. Technol., 5, (1), 207, (1992). 
5. H. Röshert, C. Eckes, H. Endo, Y. Kinoshita, T. Kudo, S. Masuda, H. Okazaki, M. Padmanaban, K-J. Przybilla, W. Spiess, N. Suehiro, H. Wengenorth, G. Pawlowski, Proc. of SPIE, 1925, 14 (1993).

6. N. Kihara, S. Saito, T. Ushirogouchi, T. Jonai, M. Nakase, The 54th Autumn Meeting of JSAP (1993) 27a-SHF-11.

7. Y. Onishi, N. Oyasato, H. Niki, R. Hayase, Y. Kobayashi, K. Sato, and M. Miyamura, J. Photopolym. Sci. Technol., 5, 47 (1992).

8. K. Asakawa, T. Ushirogouchi, M. Nakase, J. Vac. Sci. Technol. B13 (3) (1995) in press. 